\title{
Correction to: Taking Center Stage: Infants' Active Role In Language Learning
}

Catherine S. Tamis-LeMonda, Yana Kuchirko, and Daniel D. Suh

\section{Correction to:}

Chapter 3 in: M. M. Saylor, P. A. Ganea (eds.)

Active Learning from Infancy to Childhood, https://doi.org/10.1007/978-3-319-77182-3_3

The chapter 3 was inadvertently published with the incorrect chapter title "Taking Center Stage: Infants' Active Role In Language Leaning”. This has now been corrected in the chapter and the front matter pages to "Taking Center Stage: Infants' Active Role In Language Learning". 